\title{
Young patients with colorectal cancer at a tertiary hospital in Kenya, 1993-2005
}

\begin{abstract}
H. Saidi, BSc., MBChB, MMed, FCS, Department of Human Anatomy, E.o. Nyaim, MBChB, MMed, FCS, D. Karuri, MBChB, J.W. Githaiga, MBChB, MMed, FCS, School of Medicine, University of Nairobi, P.O. Box 19676-00202, Nairobi, Kenya

Correspondence to: Dr. H. Saidi, Department of Human Anatomy, College of Health Sciences, University of Nairobi, P.O. Box 30197-00100, Nairobi, Kenya. Email: hsaid2ke@yahoo.com
\end{abstract}

\section{Abstract}

BACKGROUND: The onset of colorectal cancer appears to be two to three decades earlier in developing countries. Data on whether colorectal cancer in the young has worse prognosis than in older patients is conflicting.

METHOD: Clinical charts of 70 patients $\leq 40$ years old were reviewed to determine clinical and pathological patterns and treatment outcomes. Their data were compared with a larger group of older patients treated between 1993-2005 at Kenyatta National Hospital in Nairobi, Kenya.

RESULTS: The data retrieval was highest for sub-site distribution and lowest for pathology information. Patients $\leq 40$ years of age comprised $27.3 \%$ of all colorectal cancer cases treated over the study period. There were 41 males $(58.6 \%)$ and 29 (41.4\%) females patients. The most common symptoms were abdominal pain $(76.9 \%)$, change in bowel habit (71.4\%) and rectal bleeding (54.3\%). The mean duration of symptoms was $24.6 \pm 30$ months. The rate of advanced colorectal disease (Duke C and D) was $73.5 \%$. Mean follow-up time was 5.8 months with median survival of only 6.9 months. The Duke staging, histology, symptom duration, locations of tumours, follow-up and the complication rates were similar for young and older patients.
CONCLUSION: Younger patients form a significant proportion of colorectal cancer burden. Both the clinico-pathological characteristics and treatment outcome correspond to older individuals. It is suggested that the concluded colorectal symptoms in younger patients should also be aggressively evaluated including early endoscopy. A prospective follow-up study of patients with the disease will unravel the true survival picture.

\section{Introduction}

Colorectal cancer is the second most important cause of cancer mortality in men in the Western world (1). In these countries, the disease is predominantly in the older population with only a small proportion (1-8\%) presenting in younger patients (2). It however remains debatable whether younger patients present in late stages of colorectal cancer and whether the disease in the young is more aggressive for a given stage of presentation (1).

A number of studies from the developing countries suggest the proportion of young patients may be up to six times that reported for Western literature (3-5). This report describes the clinical and pathological features of colorectal 
cancer in patients $\leq 40$ years old and compares the clinical, pathological and outcome variables of this group to older patients treated between 1993-2005 at the same institution.

\section{Patients and methods}

Seventy patients aged 40 years and younger, and treated for colorectal cancer at the Kenyatta National Hospital (KNH) between 1993-2005, were reviewed. $\mathrm{KNH}$ is the main referral hospital in the city of Nairobi and serves as the teaching hospital for the University of Nairobi. All case notes for patients with histologically proven carcinoma of the colon and rectum were retrospectively analyzed. Information obtained included age, gender, education, ethnic group, location of colorectal cancer, symptoms, tumor pathology and stage, histology, and outcome data. The modified Duke's system was used to stage the tumour. The number of patients analyzed for specific variables was highest for site and lowest for pathology data (site 70, Dukes stage 34, tumour differentiation 56). The variables were compared for patients $\leq 40$ years and those older.

The Kaplan Meir method was used to generate survival curves. Survival time was defined from the date of diagnosis to the date of death. Differences between young and old patients were analyzed statistically using the log rank test. $\mathrm{P} \leq 0.05$ was considered statistically significant.

\section{Results}

In the 13-year period studied (1993-2005), 70 patients $\leq 40$ years old were diagnosed out of a total of 259 patients with colon and rectal adenocarcinoma. Forty one $(58.6 \%)$ were male and $29(41.4 \%)$ were female. The patients' ages ranged from 10 to 40 years $($ mean $=30.1 \pm 6.9$ years). Follow-up time ranged from 1.0 to 60.0 months (mean $=5.8 \pm 10.8$ months). Most patients $(95.7 \%)$ had received at least eight years of basic education (31 primary, 22 secondary and 13 college/university education). Majority of the patients were from the Kikuyu ethnic group $(37.1 \% \mathrm{n}=26)$. Other ethnic groups represented included the Kamba $(14.3 \%, \mathrm{n}=10)$, Luhya $(7.1 \%$, $n=5)$ and Luo $(18.6 \%, n=13)$. The rest of the ethnic groupings constituted $22.9 \%(n=16)$.

The duration of symptoms ranged from 1 to 104 weeks (mean $24.6 \pm 30$ ). The most common presenting symptoms were abdominal pain $(76.9 \%)$, change in bowel habit $(71.4 \%)$, rectal bleeding $(54.3 \%)$, swelling $(34.8 \%)$, and tenesmus $(17.1 \%)$, weight loss $(14.3 \%)$ and bowel obstruction $(14.3 \%, \mathrm{n}=10)$.

As shown in Figure 1, 50\% of the tumors were located in the rectum, $17.1 \%$ in the sigmoid colon, $12.9 \%$ in the descending colon, $11.4 \%$ in cecum and $7.1 \%$ in ascending colon.

Pathology data were missing in many of the notes. Information on Duke stages was available for 34 patients. Majority were Duke stages C $(n=13)$ and $D(n=12)$. Well-differentiated or

\section{Figure 1: Location of colorectal cancer}

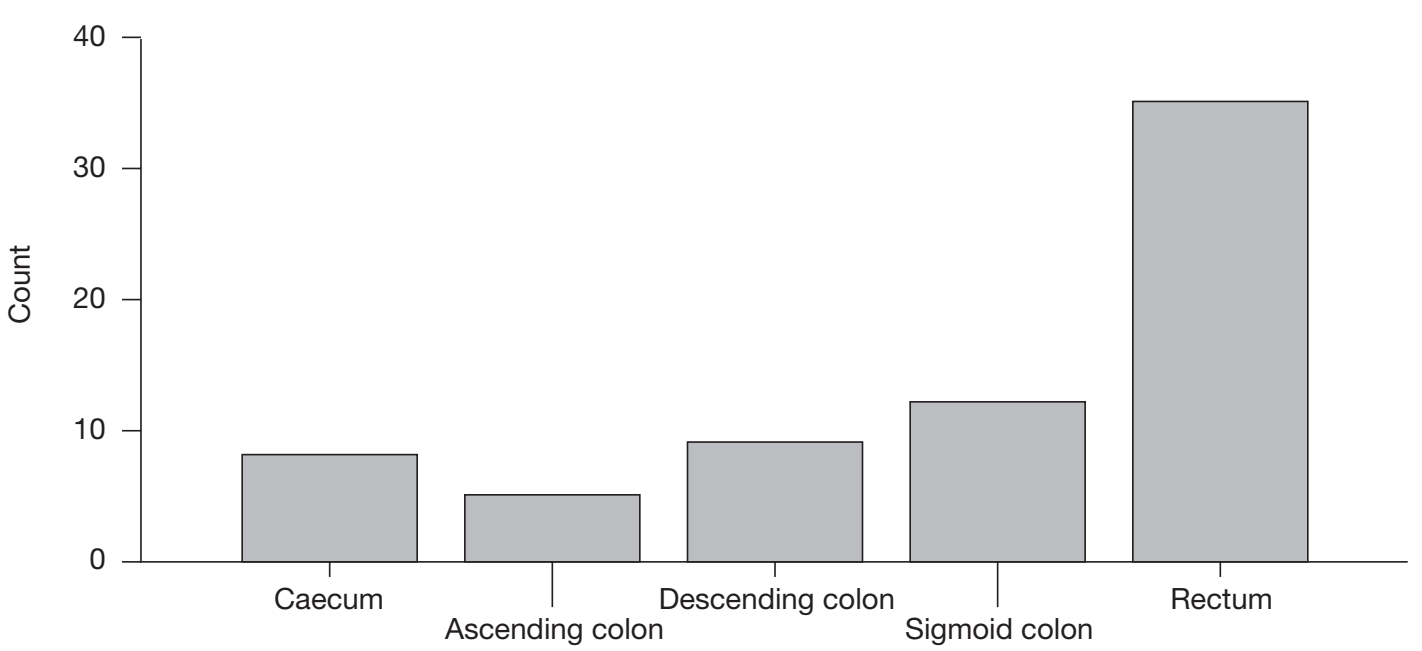

Location of lesion 
moderately differentiated histology was present in $39(69.6 \%)$ patients (Table 1$)$.

Univariate analysis showed no overall survival difference between the differentiated and undifferentiated lesions in young patients $(\mathrm{P}>0.05)$. Outcome was also similar for gender, site of lesion, nature of surgery and stage of cancer (Table 2).

Although the comorbidity rate was higher for the older patients and the cancer was poorly differentiated in the younger patient, younger and older patients groups were similar for overall survival, stages of cancer, tumour location, complications and need for blood transfusion. They differed for rate of co-morbidity (higher in older patients) and proportion of poorly differentiated histology (higher in younger patients) (Table 3 ).

The follow up period was short (mean 5.8 months, range one month to 5 years) with most patients lost to follow-up. There was no statistical difference between the follow up period for the young (5.8 \pm 10 months) as compared to older patients $(6.5 \pm 9.0$ months). Kaplan Meir analysis for survival depicted a mean overall survival of 6.9 months for patients $\leq 40$ years old and 9.4 months for older (log rank statistic 2.49, significance 0.114 ). The survival trend for the two groups is shown in Figure 2.

Table 1: Clinical data for young CRC patients

\begin{tabular}{|c|c|c|c|}
\hline Characteristic & & No. of cases & $(\%)$ \\
\hline \multirow[t]{2}{*}{ Gender } & Male & 41 & 58.6 \\
\hline & Female & 29 & 41.4 \\
\hline \multirow[t]{2}{*}{ Comorbidity } & Yes & 5 & 7.6 \\
\hline & No & 61 & 92.4 \\
\hline \multirow[t]{2}{*}{ Nature of surgery } & Elective & 42 & 72.4 \\
\hline & Emergency & 16 & 27.6 \\
\hline \multirow[t]{2}{*}{ Adjuvant treatment } & Yes & 29 & 42.6 \\
\hline & No & 39 & 57.4 \\
\hline \multirow[t]{5}{*}{ Duke stages } & $A$ & 3 & 8.8 \\
\hline & $B$ & 6 & 17.6 \\
\hline & $\mathrm{C}$ & 13 & 38.2 \\
\hline & $\mathrm{D}$ & 12 & 35.3 \\
\hline & No data/missing & 36 & \\
\hline \multirow[t]{4}{*}{ Differentiation } & Well & 21 & 37.5 \\
\hline & Moderate & 18 & 32.1 \\
\hline & Poor & 17 & 30.4 \\
\hline & No data/missing & 14 & \\
\hline \multirow[t]{5}{*}{ Tumuor location } & caecum & 8 & 11.6 \\
\hline & Ascending & 5 & 7.2 \\
\hline & Descending & 9 & 13.0 \\
\hline & Sigmoid & 12 & 17.4 \\
\hline & Rectum & 35 & 50.7 \\
\hline \multirow[t]{7}{*}{ Symptoms } & Rectal bleeding & 38 & 57.6 \\
\hline & Abdominal pain & 50 & 76.9 \\
\hline & Altered bowel habit & 45 & 71.4 \\
\hline & Weight loss & 10 & 15.4 \\
\hline & Intestinal obstruction & 10 & 15.4 \\
\hline & Abdominal swelling & 23 & 34.8 \\
\hline & Tenesmus & 12 & 18.8 \\
\hline \multirow[t]{7}{*}{ Surgery performed } & Extended resection & 22 & 32.4 \\
\hline & Palliative resection & 6 & 8.8 \\
\hline & Stoma only & 17 & 25.0 \\
\hline & Bypass & 1 & 1.4 \\
\hline & APR & 15 & 22.1 \\
\hline & Not operated & 7 & 10.3 \\
\hline & Missing & 2 & \\
\hline
\end{tabular}

Cases do not total 70 due to missing data 
Figure 2: Survival functions

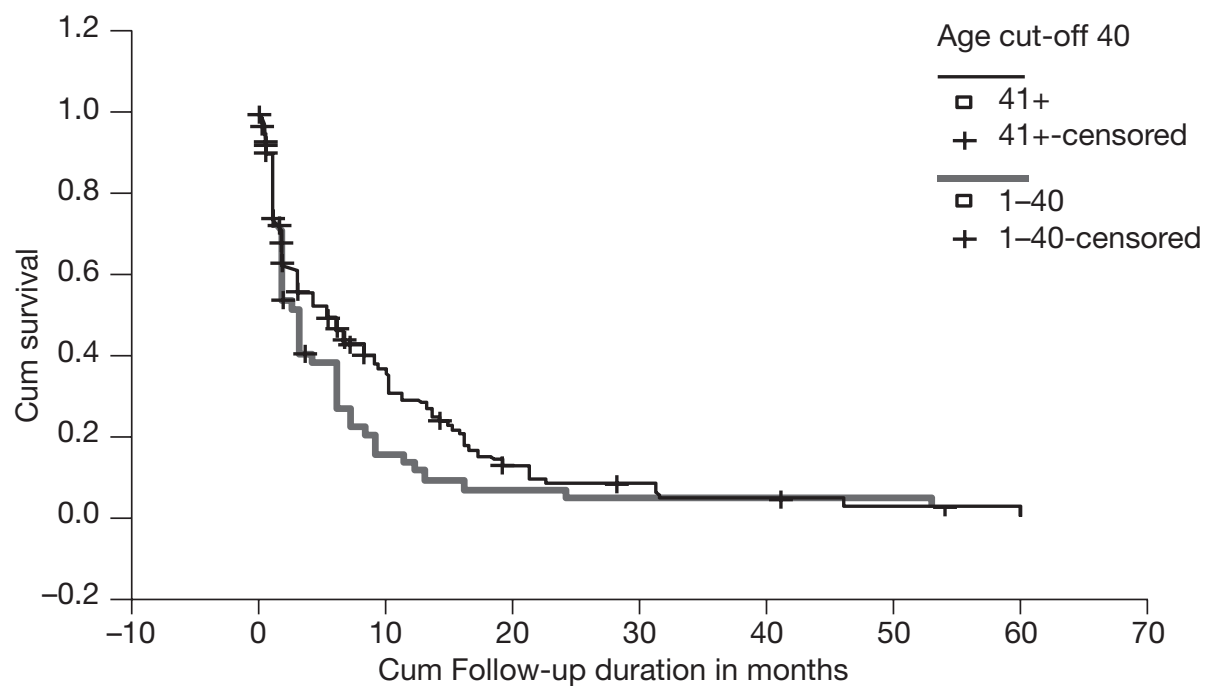

Table 2: Outcome variables for colorectal cancer in young patients at KNH

\begin{tabular}{|c|c|c|c|c|}
\hline \multirow{2}{*}{$\begin{array}{l}\text { No. of cases } \\
\text { Variable }\end{array}$} & \multicolumn{4}{|c|}{ No. of cases } \\
\hline & & Alive & Dead & $\mathrm{p}$-value \\
\hline Gender & $\begin{array}{l}\text { Male } \\
\text { Female }\end{array}$ & $\begin{array}{l}31 \\
26\end{array}$ & $\begin{array}{l}8 \\
3\end{array}$ & 0.331 \\
\hline Stage & $\begin{array}{l}\text { Duke A/B } \\
\text { Duke C/D }\end{array}$ & $\begin{array}{r}9 \\
19\end{array}$ & $\begin{array}{l}0 \\
6\end{array}$ & 0.162 \\
\hline Nature of surgery & $\begin{array}{l}\text { Elective } \\
\text { Emergency }\end{array}$ & $\begin{array}{l}37 \\
11\end{array}$ & $\begin{array}{l}4 \\
5\end{array}$ & 0.099 \\
\hline Site of tumour & $\begin{array}{l}\text { Colon } \\
\text { Rectum }\end{array}$ & $\begin{array}{l}29 \\
28\end{array}$ & $\begin{array}{l}5 \\
6\end{array}$ & 0.742 \\
\hline Differentiation & $\begin{array}{l}\text { Well/moderate } \\
\text { Poor }\end{array}$ & $\begin{array}{l}29 \\
17\end{array}$ & $\begin{array}{l}2 \\
1\end{array}$ & 0.545 \\
\hline
\end{tabular}

*Statistic - Fischer's exact test

Table 3: Comparison of colorectal cancer in older and the younger patient groups

\begin{tabular}{|c|c|c|c|c|}
\hline Factor & & Young & Old & $\mathrm{p}$-value \\
\hline Location of tumour & $\begin{array}{l}\text { Colon } \\
\text { Rectum }\end{array}$ & $\begin{array}{l}34 \\
35\end{array}$ & $\begin{array}{r}78 \\
103\end{array}$ & 0.380 \\
\hline Comorbidity & $\begin{array}{l}\text { Present } \\
\text { Absent }\end{array}$ & $\begin{array}{r}5 \\
61\end{array}$ & $\begin{array}{r}37 \\
139\end{array}$ & 0.014 \\
\hline Duke state & $\begin{array}{l}\text { A/B } \\
\text { C/D }\end{array}$ & $\begin{array}{r}9 \\
25\end{array}$ & $\begin{array}{l}27 \\
62\end{array}$ & 0.673 \\
\hline Differentiation & $\begin{array}{l}\text { Well/Moderate } \\
\text { Poor }\end{array}$ & $\begin{array}{l}39 \\
17\end{array}$ & $\begin{array}{r}106 \\
20\end{array}$ & 0.025 \\
\hline Transfusion requirement & $\begin{array}{l}\text { Yes } \\
\text { No }\end{array}$ & $\begin{array}{l}46 \\
19\end{array}$ & $\begin{array}{r}116 \\
65\end{array}$ & 0.330 \\
\hline Complications & $\begin{array}{l}\text { Yes } \\
\text { No }\end{array}$ & $\begin{array}{l}21 \\
47\end{array}$ & $\begin{array}{r}47 \\
133\end{array}$ & 0.452 \\
\hline Status at last contact & $\begin{array}{l}\text { Alive } \\
\text { Died }\end{array}$ & $\begin{array}{l}57 \\
11\end{array}$ & $\begin{array}{r}133 \\
45\end{array}$ & 0.128 \\
\hline
\end{tabular}




\section{Discussion}

The seventy patients comprised $27.3 \%$ of all patients treated for colorectal cancer at this referral hospital between 1993 and 2005. This rate is much higher than available published results from the developed economies and some developing countries. Colorectal cancer in the young is reported to occur at a rate of $1-6 \%$ of all colorectal cancers among Americans $(6,7)$. In a recent study from Istanbul, Turkey, Alici et al have reported a rate of $18 \%$ of 466 colorectal cancer cases over a 9 year period (8) while a similar rate was published from Iran (13.9\%) (9). Our results extend previous data depicting an earlier onset of colorectal cancer in African populations as compared to Caucasian ones (35). The explanation for this early development is not known.

The mean duration of symptom of 25 weeks and the high rate of advanced colorectal cancer was similar for young and older patients. It is unclear whether the delay is occasioned by the patient or the primary physician to whom the symptoms of abdominal pain, alteration of bowel habits or rectal bleeding are first presented. The symptoms reported here are typical of other reports of colorectal cancer in the young. In the studies by Farner et al (10) and Kam et al (11) bleeding was the most common reported presentation in young people. Most of the young patients in our study had received at least eight years of formal education and could form an entry point for public education on the significance of rectal bleeding as a possible initial symptom for rectal cancer.

In the current study, most tumours were located in the rectum. This distal distribution is however inconsistent with a number of published studies on young patients. Minardi et al found the disease to be evenly distributed throughout the colon and rectum in a Luisiana population (12) while Farner et al reported rectal distribution in one third of patients (10). Kam et al (11) reported a rectal distribution in $43 \%$ of Singaporean patients aged $\leq 30$ years. Tumours in patients with a predominant distal disease as in this study are expected to carry a better prognosis than those that arise more proximally. The diagnosis is usually late and the symptoms develop late in tumours proximal to the splenic flexure (1). This appears not to be the case in our group of patients as the rate of advanced disease approached $73 \%$.

There were no differences for patients younger or older than 40 years for stage, histology, sub-site distribution and transfusion requirements. These results are consistent with several previous reports (10) and do not support the conclusion that young age is a poor prognostic marker in colorectal cancer (13).

This study had limitations. Many sources of biases threaten the validity of results obtained in a retrospective study such as this one including missing data. Further symptom enquiries were not possible and details on family history and predisposing pathology known to play important role in the etiology of colorectal cancer in the young could not be established. The very short follow-up periods impact on the survival analysis as it is not possible to tell whether patients are lost to follow-up because of death or other socioeconomic reasons. This important aspect of post-treatment care is not unique to colorectal disease (14) and constitutes a serious threat to the external validity of the current results. Comparability with other long term series reporting on cohorts with long followups is remote. Prospective studies employing follow-up strategies different from the current chart review would present a better picture. Nonetheless, our results indicate that colorectal cancer in the younger age still occurs at advanced stages and the outcome for the short follow-up is poor. Efforts are recommended to ascertain the true survival pattern by improvements in follow-up and documentation.

\section{Acknowledgement}

To the management of KNH for permission to carry out the study.

\section{References}

1. Rudy D.R. and Zdon M.J. Update on colorectal cancer. Amer. Family Phys. 2000; 61: 1759-1771 
2. Parramore J.B., Wei J.P. and Yeh K.A. Colorectal cancer in patients under forty: Presentation and outcome. Amer. Surg. 1998; 64: 563-567.

3. Abou-Zeid A.A., Khafagy W., Marzouk D.M., et al. Colorectal cancer in Egypt. Dis. Colon Rectum. 2002; 45: 1255-1260.

4. Angelo N. and Dreyer L. Colorectal carcinoma-a new threat to black patients? A retrospective analysis of colorectal carcinoma received by the institute of pathology, University of Pretoria. S. Afr. Med. J. 2001; 91: 689-693.

5. AshenafiS. The frequency of large bowel cancer as seen in Addis Ababa university, pathology department. Ethiop. Med. J. 2000; 38: 277-282.

6. Cusack J.C., Giacco G.G., Cleary K., et al. Survival factors in 186 patients younger than 40 years old with colorectal adenocarcinoma. J. Amer. Coll. Surg. 1996; 183: 105-112.

7. Lee P.Y., Fletcher W.S., Sullivan E.S. and Vetto J.T. Colorectal cancer in young patients: characteristics and outcome. Amer. Surg. 1994; 60: 607-614.
8. Alici S., Aykan F., Sakar B., Bulutlar G., Kaytan E. and Topuz E. Colorectal cancer in young patients: characteristics and outcome. Tohoku. J. Exp. Med. 2003; 199: 85-93.

9. Kalavi B. Colorectal cancer and its epidemiological aspects in Iran. Turkish J. Gastroentol. 2005; 16: 248-249.

10. Farner R.E., Fisher T.L., Jacobson R.M., et al. Colon cancer in patients 40 years old or younger. BUMC proceedings. 1998; 11: 175-178.

11. Kam M.H., Eu K.W., Barben C.P. and Seow-Choen. Colorectal cancer in the young: A 12 year review of patients 30 years or less. Colorectal Dis. 2004; 6: 191-194.

12. Minardi A.J.Jr, Sitting K.M., Zibari G.B. and McDonald J.C. Colorectal cancer in the young patient. Amer. Surg. 1998; 64: 849-853.

13. Turkiewicz D., Miller B., Schache D., Cohen J. and Theile D. Young patients with colorectal cancer: How do they fare? ANZ J. Surg. 2001; 71: 707-710.

14. Ogendo S.W. Follow up of oesophageal cancer therapy at the Kenyatta National Hospital, Nairobi. East Afr. Med J. 2001; 78: 650-654. 